\title{
Beneficial effects of perioperative statins for major pulmonary resection
}

\author{
David Amar, MD, ${ }^{\mathrm{a}}$ Bernard Park, MD, ${ }^{\mathrm{b}}$ Hao Zhang, MD, ${ }^{\mathrm{a}}$ Weiji Shi, MS, ${ }^{\mathrm{d}}$ Martin Fleisher, PhD, \\ Howard T. Thaler, $\mathrm{PhD},{ }^{\mathrm{d}}$ and Valerie W. Rusch, $\mathrm{MD}^{\mathrm{b}}$
}

\begin{abstract}
Objectives: Statins improve overall outcomes after noncardiac surgery. The primary aim of the study was to determine whether use of perioperative atorvastatin reduced the rate of postoperative complications in patients undergoing pulmonary resection.
\end{abstract}

\begin{abstract}
Methods: This was a prospective, randomized, placebo-controlled, double-blind trial of patients undergoing elective pulmonary resection who received atorvastatin $(40 \mathrm{mg}$ daily) or placebo beginning 1 week before surgery and continued for 1 week postoperatively. Patient characteristics and postoperative complications were recorded. Plasma inflammatory markers were sampled at baseline, in the post-anesthesia care unit, and on postoperative day 3. Because of difficulty enrolling statin-naive patients, the study was stopped at the interim analysis.
\end{abstract}

Results: Postoperative complications occurred in 16 of 72 patients $(22 \%)$ receiving placebo and in 8 of 65 patients $(12 \%)$ receiving atorvastatin $(P=.13)$. For patients undergoing major anatomic resection, there were 24 complications in 15 of 45 placebo-treated patients and 8 complications in 7 of 43 atorvastatintreated patients $(P=.04)$. Plasma levels of $\mathrm{C}$-reactive protein, tumor necrosis factor- $\alpha$, and myeloperoxidase did not differ between the 2 treatment arms during the study.

Conclusions: After a 2-week perioperative course of atorvastatin $(40 \mathrm{mg})$ in statin-naïve patients undergoing major pulmonary resection, we found evidence of a reduction in the number of clinically important cardiovascular and pulmonary complications compared with placebo. These promising results merit evaluation in a larger, perhaps multicenter study. (J Thorac Cardiovasc Surg 2015;149:1532-8)

See related editorial on pages $1488-9$ and related article on pages $1495-501$.

Inflammatory and oxidative changes have been implicated as etiologic mechanisms for a variety of postoperative complications after thoracic surgery, such as atrial fibrillation/flutter, acute coronary syndromes, stroke, and respiratory failure. ${ }^{1-3}$ Postoperative atrial fibrillation (POAF) is a common complication, occurring in approximately $16 \%$ of all patients, with increasing frequency in elderly patients. ${ }^{4,5}$ The rate of postoperative pulmonary complications (pneumonia and respiratory

From the Departments of Anesthesiology and Critical Care Medicine, ${ }^{\text {a }}$ Surgery, ${ }^{\mathrm{b}}$ Laboratory Medicine, ${ }^{\mathrm{c}}$ and Epidemiology and Biostatistics, ${ }^{\mathrm{d}}$ Memorial Sloan Kettering Cancer Center, New York, NY.

W.S. and H.T.T. are partly supported by a National Institutes of Health Core Grant P30 CA008748.

Disclosures: David Amar reports consulting fees from ETView. Bernard Park reports lecture fees from Intuitive Surgical. All other authors have nothing to disclose with regard to commercial support.

ClinicalTrial.gov identifier: \#NCT00375518.

Received for publication June 26, 2014; revisions received Dec 5, 2014; accepted for publication Dec 7, 2014; available ahead of print Jan 23, 2015.

Address for reprints: David Amar, MD, Memorial Sloan-Kettering Cancer Center, 1275 York Ave, M-304, New York, NY 10021 (E-mail: amard@mskcc.org).

$0022-5223 / \$ 36.00$

Copyright (c) 2015 by The American Association for Thoracic Surgery

http://dx.doi.org/10.1016/j.jtcvs.2014.12.016 failure) is approximately $10 \%$, with severe lung injury resulting in mortality rates of up to $30 \%{ }^{6}$ Because these complications result in prolonged hospital stay, resource use, and long-term sequelae, prevention is essential.

Preoperative use of statins in patients with cardiovascular disease has been shown to reduce perioperative cardiovascular morbidity, but its impact in patients undergoing pulmonary resection is unknown. ${ }^{3,7}$ The presumed mechanism of the benefit of statins is through inhibition of inflammation. ${ }^{3,7,8}$ Some sequelae of lung injury after thoracic surgery include increased inflammation (C-reactive protein [CRP]), leukocyte activation (myeloperoxidase [MPO]), and other acutephase inflammatory markers, such as tumor necrosis factor alpha $(\mathrm{TNF} \alpha){ }^{1,2,9}$ MPO and CRP levels, which are also increased in patients with acute cardiovascular disease, may be reduced by statins. ${ }^{10-12}$

On the basis of promising experimental ${ }^{13-15}$ and observational studies from our institution ${ }^{9}$ and others, ${ }^{16}$ we hypothesized that compared with placebo, the use of moderate-potency atorvastatin would be associated with a decreased composite rate of clinically significant cardiovascular and pulmonary complications after lung resection. A secondary aim was to compare perioperative changes in levels of CRP, TNF $\alpha$, and MPO between the 2 treatment arms. 

Abbreviations and Acronyms
$\mathrm{CRP}=$ C-reactive protein
MPO $=$ myeloperoxidase
$\mathrm{PCU}=$ post-anesthesia care unit
$\mathrm{POAF}=$ postoperative atrial fibrillation
$\mathrm{TNF} \alpha=$ tumor necrosis factor alpha

\section{MATERIALS AND METHODS \\ Patient Population}

This was a single-center prospective, double-blind, randomized, controlled trial of perioperative moderate-dose atorvastatin versus placebo for patients undergoing elective pulmonary resection. Inclusion criteria included patients (1) undergoing elective pulmonary resection, (2) aged more than 18 years, and (3) with no active statin use. Patients were excluded if they (1) had a history of chronic atrial fibrillation, (2) were taking class I or III antiarrhythmic drugs or corticosteroids, (3) were not in sinus rhythm at the time of the screening, or (4) had abnormal liver function test results or renal insufficiency. A negative pregnancy test was required for women of childbearing age. Beta-blocker and calcium channel blocker use were continued postoperatively to avoid withdrawal. The study was approved by the institutional review board at Memorial Sloan Kettering Cancer Center, and all patients provided written, informed consent.

\section{Atorvastatin Prophylaxis}

Once enrolled, patients were randomized between atorvastatin and placebo in permuted blocks between the Department of Epidemiology and Biostatistics and the Department of Pharmacy, in accordance with good medical practice requirements. Blinding of atorvastatin and placebo pills was performed by the Department of Pharmacy, Division of Research. Atorvastatin ( $40 \mathrm{mg}$ oral daily) or placebo was started 1 week before surgery and continued for 1 week after surgery. In-hospital administration of the study drug or placebo was done by the patient's nurse unless the patient was instructed to take nothing by mouth. Each patient was asked to fill out 2 questionnaires (preoperatively and at conclusion of drug treatment) regarding any untoward effects of the study medication, as well as a diary to record intake of the medication.

\section{Inflammatory Marker Analysis}

Venous blood specimens for measurement of high-sensitivity CRP, $\mathrm{TNF} \alpha$, and MPO were obtained 7 to 10 days before surgery, on arrival at the post-anesthesia care unit (PACU), and on the morning of postoperative day 3. Serum was separated by centrifugation and stored at $-70^{\circ} \mathrm{C}$ until analysis. The high-sensitivity CRP assay was performed on the Siemens (Washington, DC) Advia 1800, which uses uniform polystyrene latex particles coated with anti-CRP antibody. The analytic range of the assay was 0.16 to $10.0 \mathrm{mg} / \mathrm{L}$. The MPO assay uses a 2-site "sandwich" enzyme-linked immunosorbent assay method, with 2 polyclonal antibodies that specifically bind to human MPO. The analytic range of MPO, using human MPO as a standard, was 1.9 to $30.0 \mathrm{ng} / \mathrm{mL}$. The TNF $\alpha$ assay uses a quantitative enzyme-linked immunosorbent assay method, with a capture monoclonal antibody specific for $\mathrm{TNF} \alpha$ that has been precoated onto a microplate well. The analytic range of this assay, using recombinant human $\mathrm{TNF} \alpha$ as a standard, was 0.5 to $32 \mathrm{pg} / \mathrm{mL}$.

\section{Anesthesia, Operation, and Postoperative Care}

All patients received premedication with midazolam and standard anesthetic management consisting of isoflurane or sevoflurane in oxygen supplemented with intravenous fentanyl and hydromorphone as needed. Intentional crystalloid restriction $(<25 \mathrm{~mL} / \mathrm{kg})$ during surgery was attempted in all patients. The operations were performed using minimally invasive video-assisted thoracic surgery or thoracotomy approaches designed to completely remove all neoplastic disease, along with ipsilateral mediastinal lymph node sampling or dissection. Postoperative pain relief was provided by continuous administration of epidural hydromorphone and bupivacaine $0.05 \% \quad(\mathrm{n}=121)$ or patient-controlled intravenous hydromorphone analgesia $(\mathrm{n}=16$; nonanatomic lung resection). After an overnight stay in the PACU, patients were transferred to the thoracic surgical floor on the first postoperative day. Major postoperative cardiac or pulmonary complications were recorded throughout the hospital stay. A research assistant monitored patients for cardiac or pulmonary complications as outpatients and queried patients about intercurrent hospitalizations or emergency department visits. An investigator reviewed these medical records. Continuous dual-lead electrocardiogram telemetry tracings (72-96 hours) after surgery were reviewed by an experienced technician and a cardiologist.

\section{Statistical Analysis}

We had originally planned a larger study $(n=480)$ using a composite of cardiovascular outcomes as the primary end point in patients aged more than 55 years scheduled for anatomic resections. Soon after the start of the trial, new data were published on the greater efficacy of atorvastatin to reduce POAF,${ }^{17}$ and it became clear that a significant number of preoperative patients were already taking statin mediation. We recalculated and estimated that a sample size of 276 patients (138 patients per arm) undergoing lung resection would provide an $80 \%$ chance of observing a significant difference $(P<.05)$ in the proportion of patients experiencing a major postoperative cardiovascular or pulmonary complication of $27 \%$ versus $13 \%$. Because of the difficulty of enrolling patients, the study was stopped at the interim analysis (Figure 1). Among patients who had an anatomic resection $(\mathrm{n}=88)$, a subgroup analysis was performed to assess the difference in overall complication rates for all hypothetical random assignments (permutations) of the treatment arm labels (45 "atorvastatin" + 43 "placebo") to the collection of 88 numbers, each representing the actually observed count of major complications $(0,1,2,3$, or 4$)$ in the original, combined sample. The 2 -sided $P$ value is the proportion of such permutations yielding an absolute difference in overall complication rates at least as large as what was calculated for the actual treatment assignment. SAS version 9.2 (SAS Institute Inc, Cary, NC) was used to determine differences in patient and operative characteristics between the 2 arms and between patients with and without complications. Data are presented as mean \pm standard deviation, median (quartiles) for skewed data, or $\mathrm{n}(\%)$.

\section{RESULTS}

From October 2006 to May 2010, a total of 3326 patients were evaluated and 164 patients met the inclusion criteria and were enrolled (Figure 1). Twenty-seven patients were excluded after enrollment, and 137 patients (88 anatomic resections and 49 wedge resections) received atorvastatin or placebo. The 2 treatment groups did not differ in terms of patient characteristics or surgical data, both for the entire study population (Table 1) and for the subset of patients who underwent anatomic lung resection (Table 2). Postoperative complications occurred in 16 of 72 patients $(22 \%)$ receiving placebo and in 8 of 65 patients $(12 \%)$ receiving atorvastatin $(P=.13)$. The rate of complications was higher after anatomic lung resection compared with wedge resection $(22 / 88,25 \%$ vs $2 / 49,4 \%, P=.002)$. In the wedge resection group, POAF developed in 1 patient and pneumonia developed in 1 patient. The rates of major complications for those who underwent anatomic lung resection by treatment arm are shown in Table 3. Patients treated with atorvastatin had a trend toward decreased 


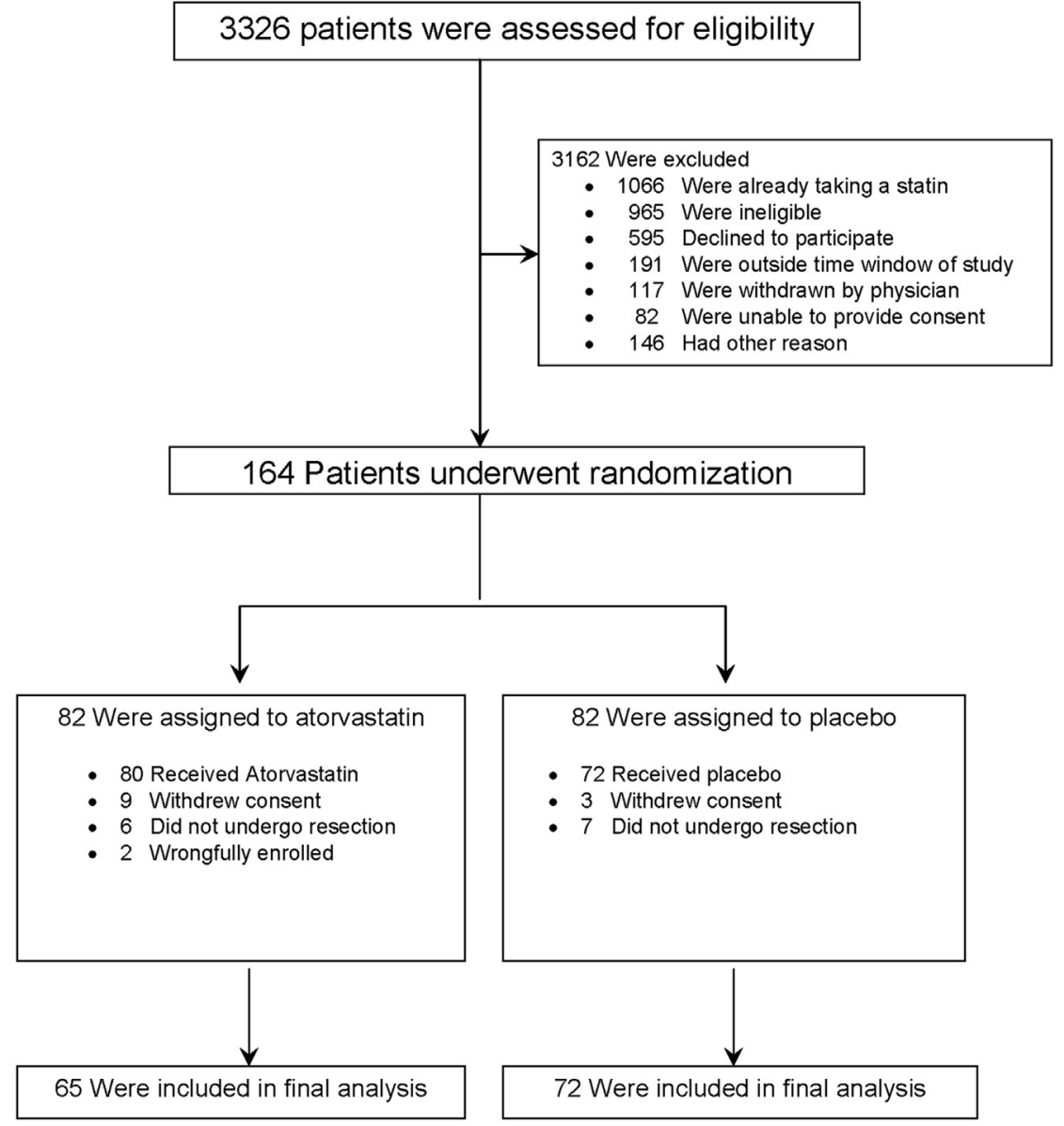

FIGURE 1. Enrollment and randomization.

complications in each category. For example, the incidence of POAF in the treated group was approximately $50 \%$ lower than in the placebo group. In addition, a permutation test analysis showed that atorvastatin-treated patients had an approximately 3 -fold decrease in overall complication rate of 0.186 compared with 0.533 per patient who received placebo $(P=.04)$. After anatomic lung resection, the combined rate of pneumonia and respiratory failure was $13 \%(6 / 45)$ in atorvastatin-treated patients versus $2 \%$ $(1 / 43)$ in placebo-treated patients $(P=.11)$. The incidence of air leak was approximately $10 \%$ in each group $(P=.99)$.

Data on inflammatory markers for the entire study population and those undergoing anatomic resection are shown in Tables 4 and 5, respectively. There were no significant differences between the 2 groups in levels of any inflammatory marker during the study period. Among patients who underwent anatomic pulmonary resection, pain scores significantly decreased from PACU to postoperative day 3 in both groups $(P=.002)$, but there were no significant differences in daily average pain scores between the 2 treatment arms (data not shown). The median follow-up time for survivors for all patients was 35.4 months (range, 17.3-59.7 months). Twenty-six patients who underwent anatomic resection died during the follow-up. There was no significant difference in overall survival between the treatment arms $(P=.76)$.

Atorvastatin was well tolerated, and no patient reported any serious adverse events related to the medication. Of the 4 patients in whom acute respiratory distress syndrome developed, 1 received the full course of atorvastatin and 3 of the patients were in the placebo arm and received at least 3 days of study drug before becoming unable to take anything by mouth or requiring intubation. Before surgery, all self-reported diaries were collected and described: Constitutional symptoms, such as diarrhea $(n=2)$, leg cramps $(\mathrm{n}=1)$, flushing $(\mathrm{n}=1)$, and back pain $(\mathrm{n}=1)$, were reported in atorvastatin-treated patients, and diarrhea $(\mathrm{n}=1)$ and muscle pain $(\mathrm{n}=1)$ were reported in placebo-treated patients. After surgery, 8 of 65 diaries in the atorvastatin arm and 10 of 72 diaries in the placebo arm were not returned. No patient reported any side effect.

\section{DISCUSSION}

\section{Main Findings}

When anatomic and wedge resection cases were considered together, a 2-week perioperative (1 week 
TABLE 1. Characteristics of all study patients

\begin{tabular}{|c|c|c|c|}
\hline $\begin{array}{c}\text { Period, } \\
\text { characteristic }\end{array}$ & $\begin{array}{l}\text { Placebo } \\
(\mathrm{n}=72)\end{array}$ & $\begin{array}{l}\text { Atorvastatin } \\
(\mathrm{n}=65)\end{array}$ & $\begin{array}{c}P \\
\text { value }\end{array}$ \\
\hline \multicolumn{4}{|l|}{ Preoperative } \\
\hline Age, y & $63 \pm 9$ & $63 \pm 10$ & .90 \\
\hline Male & $43(60)$ & $37(57)$ & .74 \\
\hline BMI, $\mathrm{kg} / \mathrm{m}^{2}$ & $27 \pm 5$ & $27 \pm 6$ & .81 \\
\hline \multicolumn{4}{|l|}{ ASA score } \\
\hline 2 & $36(50)$ & $37(57)$ & .42 \\
\hline 3 & $36(50)$ & $28(43)$ & \\
\hline Smoking & $59(82)$ & $49(75)$ & .35 \\
\hline Coronary artery disease & $2(3)$ & $2(3)$ & 1.00 \\
\hline Hypertension & $25(35)$ & $22(34)$ & .91 \\
\hline Diabetes mellitus & $4(6)$ & $5(8)$ & .74 \\
\hline Chemotherapy & $24(33)$ & $23(35)$ & .80 \\
\hline Beta-blockers & $10(14)$ & $9(14)$ & .99 \\
\hline Diltiazem & $1(1)$ & $4(6)$ & .19 \\
\hline $\mathrm{FEV}_{1} \%$ predicted & $87 \pm 20$ & $87 \pm 20$ & .94 \\
\hline DLCO $\%$ predicted & $78 \pm 19$ & $82 \pm 21$ & .38 \\
\hline \multicolumn{4}{|l|}{ Intraoperative } \\
\hline Anatomic lung resection & $43(60)$ & $44(68)$ & .54 \\
\hline VATS & $30(42)$ & $21(32)$ & .26 \\
\hline Lobectomy & $11(15)$ & $8(12)$ & \\
\hline Wedge & $19(26)$ & $13(20)$ & \\
\hline Blood loss, L & $0.13(0.05-0.33)$ & $0.10(0.05-0.30)$ & $.64 \dagger$ \\
\hline Total fluid input, L & $1.0(0.8-1.5)$ & $1.0(0.7-1.5)$ & $.81 \dagger$ \\
\hline Epidural analgesia & $61(85)$ & $60(92)$ & .17 \\
\hline \multicolumn{4}{|l|}{ Postoperative } \\
\hline Length of hospital stay, $d$ & $4(2-7)$ & $4(3-6)$ & $.94 \ddagger$ \\
\hline
\end{tabular}

Values are mean $\pm \mathrm{SD}$, median (quartiles), or $\mathrm{n}(\%)$. BMI, Body mass index; $A S A$, American Society of Anesthesiologists; $F E V_{1}$, forced expiratory volume in 1 second; $D L C O$, lung diffusion capacity of carbon monoxide; VATS, video-assisted thoracic surgery. ${ }^{*}$ By $t$ test, chi-square test, or Fisher exact test, unless otherwise indicated. $\dagger$ Based on log-transformed data. ‡By Wilcoxon rank-sum test.

preoperatively and 1 week postoperatively) course of moderate-potency atorvastatin was not associated with a significant difference in overall complication rate or in any of the systemic markers of inflammation between groups during the study period. However, in a subset analysis of patients who had undergone anatomic resection, atorvastatin use was associated with a reduced overall rate of major postoperative cardiovascular and pulmonary complications. The impetus for performing a subset analysis of patients only undergoing anatomic resection was the fact that it is well established that the expected complication rate from wedge resections is significantly lower than from anatomic resections, particularly lobectomy. ${ }^{6,18,19}$ Although there was no difference in the rate of wedge resection between groups, the substantial percentage of cases may have reduced the ability to discern a difference. There were no significant differences in baseline or other clinical characteristics between groups that may have affected the observed results. For instance, the use of a video-assisted thoracic surgery approach, which is associated with a lower morbidity rate for anatomic resection compared with thoracotomy, ${ }^{18}$ was
TABLE 2. Characteristics of patients who underwent anatomic lung resection

\begin{tabular}{|c|c|c|c|}
\hline $\begin{array}{c}\text { Period, } \\
\text { characteristic }\end{array}$ & $\begin{array}{l}\text { Placebo } \\
(\mathrm{n}=45)\end{array}$ & $\begin{array}{l}\text { Atorvastatin } \\
(\mathrm{n}=\mathbf{4 3})\end{array}$ & $\begin{array}{c}P \\
\text { value* }^{*}\end{array}$ \\
\hline \multicolumn{4}{|l|}{ Preoperative } \\
\hline Age, y & $65 \pm 9$ & $65 \pm 9$ & .88 \\
\hline Male & $27(60)$ & $23(53)$ & .54 \\
\hline BMI, $\mathrm{kg} / \mathrm{m}^{2}$ & $27 \pm 5$ & $27 \pm 6$ & 1.00 \\
\hline \multicolumn{4}{|l|}{ ASA score } \\
\hline 2 & $21(47)$ & $23(53)$ & .52 \\
\hline 3 & $24(53)$ & $20(47)$ & \\
\hline Beta-blocker & $8(18)$ & $6(14)$ & .62 \\
\hline Diltiazem & $1(2)$ & $4(9)$ & .20 \\
\hline Smoking & $43(96)$ & $36(84)$ & .09 \\
\hline Coronary artery disease & $1(2)$ & $2(5)$ & .61 \\
\hline Hypertension & $17(38)$ & $13(30)$ & .46 \\
\hline Diabetes mellitus & $3(7)$ & $3(7)$ & 1.00 \\
\hline Chemotherapy & $16(36)$ & $17(40)$ & .70 \\
\hline $\mathrm{FEV}_{1} \%$ predicted & $84 \pm 21$ & $89 \pm 17$ & .27 \\
\hline DLCO $\%$ predicted & $75 \pm 19$ & $82 \pm 21$ & .11 \\
\hline \multicolumn{4}{|l|}{ Intraoperative } \\
\hline VATS lobectomy & $11(24)$ & $8(19)$ & .51 \\
\hline Open thoracotomy & $34(76)$ & $35(81)$ & \\
\hline Pneumonectomy & 3 & 5 & \\
\hline Bilobectomy & 4 & 2 & \\
\hline Lobectomy & 26 & 27 & \\
\hline Segmentectomy & 1 & 1 & \\
\hline Blood loss, L & $0.20(0.10-0.37)$ & $0.20(0.10-0.40)$ & $.87 \dagger$ \\
\hline Total fluid input, L & $1.2(0.9-1.6)$ & $1.2(1.0-1.9)$ & $.67 \dagger$ \\
\hline \multicolumn{4}{|l|}{ Postoperative } \\
\hline Length of hospital stay, $d$ & $5(4-9)$ & $5(4-6)$ & $.19 \ddagger$ \\
\hline
\end{tabular}

Data are mean $\pm \mathrm{SD}$, median (quartiles), or $\mathrm{n}(\%) . B M I$, Body mass index; $A S A$, American Society of Anesthesiologists; $F E V_{1}$, forced expiratory volume in 1 second; $D L C O$, lung diffusion capacity of carbon monoxide; VATS, video-assisted thoracic surgery. *By $t$ test, chi-square test, or Fisher exact test, unless otherwise indicated. $\dagger$ Based on log transformed data. ŁBy Wilcoxon rank-sum test.

similar between the treatment groups in this study. A recent systematic review and meta-analysis showed that perioperative statins can reduce outcomes such as myocardial infarction and death among patients undergoing cardiac and noncardiac surgery, as well as POAF among patients undergoing cardiac surgery. ${ }^{7}$ The most common cardiovascular complication in our study was POAF, which occurred in 18 of 88 patients $(20 \%)$ who underwent anatomic lung resection. The magnitude of reduction in POAF attributed to statins in the studies in the metaanalysis $^{7}$ was similar to the trend seen in our study, approximately $40 \%$. Atorvastatin is now included as a class IIb prevention measure for POAF in statin-naïve patients in the 2014 American Association for Thoracic Surgery guidelines for the prevention and management of atrial fibrillation and flutter after thoracic surgical procedures. ${ }^{19}$ We also observed a similar trend in the reduced combined rate of pneumonia and respiratory failure among atorvastatin-treated patients after anatomic lung resection. In a population-based cohort study of 29,900 patients, 
TABLE 3. In-hospital complications in patients who underwent anatomic lung resection

\begin{tabular}{lccr}
\hline \multicolumn{1}{c}{ Complication } & $\begin{array}{c}\text { Placebo } \\
(\mathbf{n}=\mathbf{4 5})\end{array}$ & $\begin{array}{c}\text { Atorvastatin } \\
(\mathbf{n}=\mathbf{4 3 )}\end{array}$ & $\begin{array}{c}\boldsymbol{P} \\
\text { value }\end{array}$ \\
\hline Pneumonia & $3(7)$ & $0(0)$ & .24 \\
Acute respiratory failure & $3(7)$ & $1(2)$ & .62 \\
Atrial fibrillation & $12(27)$ & $6(14)$ & .14 \\
Myocardial infarction & $2(4)$ & $0(0)$ & .49 \\
Deep vein thrombosis & $1(2)$ & $0(0)$ & 1.00 \\
In-hospital mortality & $3(7)$ & $1(2)$ & .62 \\
\hline
\end{tabular}

Data are $\mathrm{n}(\%)$.

preadmission use of statins was associated with decreased mortality after hospitalization for pneumonia. ${ }^{20}$ Statins also have been shown to modify the course and severity of sepsis and outcomes related to sepsis. ${ }^{21}$ However, in another study, statins were not shown to protect against progression of lung injury or associated organ failure in a cohort of patients with acute lung injury. ${ }^{22}$

\section{Comparison With the Literature}

Atorvastatin did not blunt or modify the changes seen in any of the measured markers of inflammation. The duration and dosage of preoperative statin treatment have varied widely between studies. Much of our understanding of the effects of perioperative statins on the inflammatory response to surgery has been derived from work performed to reduce POAF. ${ }^{17,23}$ We chose a moderate-potency dose of atorvastatin $(40 \mathrm{mg})$, because it has proven clinical efficacy in the routine treatment of hypercholesterolemia. In a study

TABLE 4. Perioperative changes in inflammatory markers by treatment arm

\begin{tabular}{|c|c|c|c|c|}
\hline \multirow[b]{2}{*}{ Marker, time point } & \multicolumn{2}{|c|}{ Placebo $(n=72)$} & \multicolumn{2}{|c|}{ Atorvastatin $(n=65)$} \\
\hline & $\mathbf{N}$ & $\begin{array}{c}\text { Median } \\
\text { (quartiles) }\end{array}$ & $\mathbf{N}$ & $\begin{array}{c}\text { Median } \\
\text { (quartiles) }\end{array}$ \\
\hline \multicolumn{5}{|l|}{$\mathrm{CRP}, \mathrm{mg} / \mathrm{dL}$} \\
\hline Preoperative & 67 & $0.3(0.1-0.6)$ & 60 & $0.3(0.1-0.5)$ \\
\hline PACU & 58 & $0.3(0.1-0.7)$ & 61 & $0.2(0.1-0.7)$ \\
\hline Postoperative day 3 & 44 & $13.7(10.0-17.9)$ & 47 & $11.3(8.1-15.7)$ \\
\hline \multicolumn{5}{|l|}{$\mathrm{MPO}, \mathrm{ng} / \mathrm{mL}$} \\
\hline Preoperative & 67 & $392(240-584)$ & 57 & 369 (246-577) \\
\hline $\mathrm{PACU}$ & 65 & 439 (289-668) & 64 & $476(256-793)$ \\
\hline Postoperative day 3 & 42 & $532(276-1200)$ & 46 & $813(354-1132)$ \\
\hline \multicolumn{5}{|l|}{$\mathrm{TNF} \alpha, \mathrm{pg} / \mathrm{mL}$} \\
\hline Preoperative & 67 & $2.8(1.3-9.2)$ & 61 & $2.9(1.3-12.8)$ \\
\hline PACU & 66 & $1.5(1.0-2.6)$ & 64 & $1.5(0.9-4.0)$ \\
\hline Postoperative day 3 & 42 & $2.7(1.6-6.0)$ & 48 & $3.1(1.6-8.9)$ \\
\hline
\end{tabular}

Values are median (quartiles) and analyzed using logarithm-transformed data Repeated-measures analysis of variance was performed to assess the changes of CRP, MPO, and TNF $\alpha$ levels between PACU and preoperatively. Postoperative day 3 was not included in the analysis because approximately one third of the patients were discharged before the levels could be drawn. Both groups significantly increased in MPO and decreased in TNF $\alpha$ over time $(P=.004$ and $P<.0001$, respectively). There were no significant differences in inflammatory markers between the 2 arms at each time point. $C R P$, C-reactive protein; $M P O$, myeloperoxidase; $P A C U$, post-anesthesia care unit; $T N F \alpha$, tumor necrosis factor alpha.
TABLE 5. Inflammatory marker changes in patients who underwent anatomic lung resection

\begin{tabular}{|c|c|c|c|c|}
\hline \multirow[b]{2}{*}{ Marker, time point } & \multicolumn{2}{|c|}{ Placebo $(n=45)$} & \multicolumn{2}{|c|}{ Atorvastatin $(n=43)$} \\
\hline & $\mathbf{N}$ & $\begin{array}{c}\text { Median } \\
\text { (quartiles) }\end{array}$ & $\mathbf{N}$ & $\begin{array}{c}\text { Median } \\
\text { (quartiles) }\end{array}$ \\
\hline \multicolumn{5}{|l|}{$\mathrm{CRP}, \mathrm{mg} / \mathrm{dL}$} \\
\hline Preoperative & 41 & $0.3(0.1-0.5)$ & 41 & $0.3(0.2-0.4)$ \\
\hline PACU & 37 & $0.4(0.1-0.8)$ & 42 & $0.3(0.1-0.7)$ \\
\hline Postoperative day 3 & 38 & $13.6(9.9-18.0)$ & 34 & $11.7(8.9-15.6)$ \\
\hline \multicolumn{5}{|l|}{ MPO, ng/mL } \\
\hline Preoperative & 41 & $344(200-582)$ & 38 & $283(196-476)$ \\
\hline $\mathrm{PACU}$ & 43 & 406 (276-624) & 42 & $498(252-805)$ \\
\hline Postoperative day 3 & 36 & $488(252-1088)$ & 34 & $856(354-1132)$ \\
\hline \multicolumn{5}{|l|}{$\mathrm{TNF} \alpha, \mathrm{pg} / \mathrm{mL}$} \\
\hline Preoperative & 41 & $4.2(2.0-8.2)$ & 42 & $3.5(1.3-13.5)$ \\
\hline $\mathrm{PACU}$ & 44 & $1.7(1.1-3.0)$ & 42 & $1.8(1.1-4.1)$ \\
\hline Postoperative day 3 & 36 & $2.6(1.6-5.6)$ & 35 & $4.1(1.8-13.9)$ \\
\hline
\end{tabular}

Values are median (quartiles) and analyzed using logarithm-transformed data. Repeated-measures analysis of variance was performed to assess the changes of CRP, MPO, and TNF $\alpha$ levels. CRP significantly increased from PACU to postoperative day $3(P<.0001)$. MPO significantly increased from the preoperative day to PACU $(P=.002)$. TNF $\alpha$ level significantly decreased from the preoperative day to PACU $(P=.001)$ and then increased from PACU to postoperative day 3 $(P=.003)$. There were no significant differences in the inflammatory markers between the 2 arms over time. $C R P$, C-reactive protein; $M P O$, myeloperoxidase; $P A C U$, post-anesthesia care unit; $T N F \alpha$, tumor necrosis factor alpha.

similar to ours in design, atorvastatin at $40 \mathrm{mg}$ for 7 days before and 7 days after cardiac surgery did not reduce CRP levels but did reduce rates of POAF by approximately $40 \%$, from $57 \%$ (56/99) in placebo-treated patients to $35 \%$ $(35 / 101)$ in atorvastatin-treated patients. ${ }^{17} \mathrm{We}$ found a trend of lower POAF rate and no effect on CRP in patients receiving atorvastatin. Although it is possible that had we used higher atorvastatin doses in our study, this may have affected our inflammatory marker results, but this is unlikely because other investigators have examined the effects of maximal doses of atorvastatin $(80 \mathrm{mg})$ on inflammatory marker levels and did not find any differences after 1 week of treatment. ${ }^{24}$ In contrast, nonsurgical patients with acute coronary syndromes who were randomized to receive atorvastatin had significant reductions in CRP and MPO levels 1 week after therapy, compared with patients who received placebo. ${ }^{12} \mathrm{Kim}$ and colleagues ${ }^{25}$ showed that patients in whom atrial fibrillation developed after coronary artery bypass grafting had greater nicotinamide adenosine dinucleotide phosphate oxidase activity in atrial tissue but did not differ in systemic markers of oxidative stress, compared with patients in whom POAF did not develop. Further work from these investigators showed that preoperative treatment with atorvastatin $(40 \mathrm{mg}$ for 3 days) reduced levels of myocardial nicotinamide adenosine dinucleotide phosphate oxidase activity but not plasma levels of oxidative stress markers, such as malonyldialdehyde. ${ }^{26}$ Plasma markers of oxidative stress may not have sufficient specificity to accurately reflect changes that occur 
in the human atrium, particularly when activation of a complex of oxidases occurs during the course of surgery. Likewise, in larger studies of patients undergoing cardiac surgery, systemic markers of inflammation, such as CRP, have not been shown to correlate with markers of myocardial fibrosis and inflammation. ${ }^{27,28}$ We speculate that the beneficial effects of statins on postoperative clinical outcomes represent the direct activity of statins on target organs, such as the heart or vascular endothelium.

\section{Study Limitations}

At the recommendation of the Data and Safety Monitoring Board, we stopped the trial early (at the interim analysis) because of increasing difficulty in enrolling statin-naive patients and the resultant inability to complete this study in a reasonable amount of time. Although we found a modest statistical association between atorvastatin use and reduced perioperative morbidity, we acknowledge that our sample size was small. In addition, there were a significant proportion of subjects who underwent nonanatomic lung resection (wedge), for which the expected complication rate should be low. Although the subgroup analysis was performed to address this issue, the optimal situation would have been to complete patient accrual. Despite the variable doses of statins used between studies, our findings are consistent with those in the literature on patients undergoing cardiac surgery. ${ }^{22-26}$

\section{CONCLUSIONS}

In statin-naïve patients undergoing anatomic lung resection, a 2-week perioperative course of atorvastatin $(40 \mathrm{mg})$ was associated with a reduction in the number of clinically important cardiovascular and pulmonary complications compared with placebo. The groups did not differ significantly in any systemic marker of inflammation during the study period. These promising results in patients undergoing anatomic pulmonary resection merit further evaluation in a larger multicenter, randomized, controlled trial before recommendation as standard clinical practice.

The authors thank Dr Mark Klang, Core Manager, Research Pharmacy, for help with preparation of the blinded capsules, and Rita Gonzalez, for help with inflammatory marker analysis.

\section{References}

1. Craig SR, Leaver HA, Yap PL, Pugh GC, Walker WS. Acute phase responses following minimal access and conventional thoracic surgery. Eur J Cardiothorac Surg. 2001;20:455-63.

2. Williams EA, Quinlan GJ, Goldstraw P, Gothard JW, Evans TW. Postoperative lung injury and oxidative damage in patients undergoing pulmonary resection. Eur Respir J. 1998;11:1028-34.

3. Le Manach Y, Coriat P, Collard CD, Riedel B. Statin therapy within the perioperative period. Anesthesiology. 2008:108:1141-6.

4. Amar D, Zhang H, Shi W, Downey RJ, Bains MS, Park BJ, et al. Brain natriuretic peptide and risk of atrial fibrillation after thoracic surgery. J Thorac Cardiovasc Surg. 2012;144:1249-53.
5. Amar D, Roistacher N, Rusch VW, Leung DHY, Ginsburg I, Zhang H, et al. Effects of diltiazem prophylaxis on the incidence and clinical outcome of atrial arrhythmias after thoracic surgery. J Thorac Cardiovasc Surg. 2000;120: 790-8.

6. Amar D, Munoz D, Shi W, Zhang H, Thaler HT. Clinical prediction rule for pulmonary complications after thoracic surgery for primary lung cancer. Anesth Analg. 2010;110:1343-8.

7. Chopra V, Wesorick DH, Sussman JB, Greene T, Rogers M, Froehlich JB, et al. Effect of perioperative statins on death, myocardial infarction, atrial fibrillation, and length of stay: a systematic review and meta-analysis. Arch Surg. 2012;147: 181-9.

8. Glynn RJ, Danielson E, Fonseca FA, Genest J, Gotto AM Jr, Kastelein JJ, et al. A randomized trial of rosuvastatin in the prevention of venous thromboembolism. N Engl J Med. 2009;360:1851-61.

9. Amar D, Zhang H, Heerdt PM, Park B, Fleisher M, Thaler HT. Statin use is associated with a reduction in atrial fibrillation after noncardiac thoracic surgery independent of C-reactive protein. Chest. 2005;128:3421-7.

10. Macin SM, Perna ER, Farías EF, Franciosi V, Cialzeta JR, Brizuela M, et al. Atorvastatin has an important acute anti-inflammatory effect in patients with acute coronary syndrome: results of a randomized, double-blind, placebo-controlled study. Am Heart J. 2005;149:451-7.

11. Brennan ML, Penn MS, Van Lente F, Nambi V, Shishehbor MH, Aviles RJ, et al. Prognostic value of myeloperoxidase in patients with chest pain. N Engl J Med. 2003;349:1595-604.

12. Zhou T, Zhou SH, Qi SS, Shen XQ, Zeng GF, Zhou HN. The effect of atorvastatin on serum myeloperoxidase and CRP levels in patients with acute coronary syndrome. Clin Chim Acta. 2006;368:168-72.

13. Jacobson JR, Barnard JW, Grigoryev DN, Ma S-F, Tuder RM, Garcia JGN Simvastatin attenuates vascular leak and inflammation in murine inflammatory lung injury. Am J Physiol Lung Cell Mol Physiol. 2005;288: L1026-32.

14. Kumar AP, Reynolds WF. Statins downregulate myeloperoxidase gene expression in macrophages. Biomed Biophys Res Commun. 2005;331:442-51.

15. Shishehbor MH, Brennan M-L, Aviles RJ, Fu X, Penn MS, Sprecher DL, et al Statins promote potent systemic antioxidant effects through specific inflammatory pathways. Circulation. 2003;108:426-31.

16. Lindenauer PK, Pekow P, Wang K, Gutierrez B, Benjamin EM. Lipid-lowering therapy and in-hospital mortality following major noncardiac surgery. JAMA. 2004;291:2092-9.

17. Patti G, Chello M, Candura D, Pasceri V, D'Ambrosio A, Covino E, et al Randomized trial of atorvastatin for reduction of postoperative atrial fibrillation in patients undergoing cardiac surgery: results of the ARMYDA-3 (Atorvastatin for the Reduction of Myocardial Dysrhythmia After cardiac surgery) study. Circulation. 2006;114:1455-61

18. Flores RM, Park BJ, Dycoco J, Aronova A, Hirth Y, Rizk NP, et al. Lobectomy by video-assisted thoracic surgery (VATS) versus thoracotomy for lung cancer J Thorac Cardiovasc Surg. 2009;138:11-8.

19. Frendl G, Sodickson AC, Chung MK, Waldo AL, Gersh BJ, Tisdale JE, et al. 2014 AATS Guidelines for the Prevention and Management of Peri-Operative Atrial Fibrillation and Flutter (POAF) for Thoracic Surgical Procedures. J Thorac Cardiovasc Surg. 2014;148:e153-93.

20. Thomsen RW, Riis A, Kornum JB, Christensen S, Johnsen SP, Sørensen HT Preadmission use of statins and outcomes after hospitalization with pneumonia: population-based cohort study of 29,900 patients. Arch Intern Med. 2008;168: 2081-7.

21. Terblanche M, Almog Y, Rosenson RS, Smith TS, Hackam DG. Statins and sepsis: multiple modifications at multiple levels. Lancet Infect Dis. 2007;7: 358-68.

22. Kor DJ, Iscimen R, Yilmaz M, Brown MJ, Brown DR, Gajic O. Statin administration did not influence the progression of lung injury or associated organ failures in a cohort of patients with acute lung injury. Intensive Care Med. 2009;35:1039-46.

23. Song YB, On YK, Kim JH, Shin DH, Kim JS, Sung J, et al. The effects of atorvastatin on the occurrence of postoperative atrial fibrillation after off-pump coronary artery bypass grafting surgery. Am Heart J. 2008;156: 373.e9-16.

24. Karimi A, Bidhendi LM, Rezvanfard M, Bina P, Yousefi A, Molai M, et al. The effect of a high dose of atorvastatin on the occurrence of atrial fibrillation after coronary artery bypass grafting. Ann Thorac Surg. 2012;94:8-12.

25. Kim YM, Kattach H, Ratnatunga C, Pillai R, Channon KM, Casadei B. Association of atrial nicotinamide adenine dinucleotide phosphate oxidase 
activity with the development of atrial fibrillation after cardiac surgery. JAm Coll Cardiol. 2008:51:68-74.

26. Antoniades C, Demosthenous M, Reilly S, Margaritis M, Zhang MH, Antonopoulos A, et al. Myocardial redox state predicts in-hospital clinical outcome after cardiac surgery effects of short-term pre-operative statin treatment. J Am Coll Cardiol. 2012;59:60-70.
27. Goette A, Juenemann G, Peters B, Klein HU, Roessner A, Huth C, et al. Determinants and consequences of atrial fibrosis in patients undergoing open-heart surgery. Cardiovasc Res. 2002;54:390-6.

28. Ahlsson AJ, Bodin L, Lundblad OH, Englund AG. Postoperative atrial fibrillation is not correlated to C-reactive protein. Ann Thorac Surg. 2007;83: $1332-7$.

Readers who found these articles interesting may also like to read the following papers found in recent and future issues of our sister publications, Seminars in Thoracic and Cardiovascular Surgery and Operative Techniques in Thoracic and Cardiovascular Surgery!

\section{General Thoracic Surgery: Thoracic Oncology}

News and Views: Marc de Perrot. Novel induction therapies for pleural mesothelioma. Semin Thorac Cardiovasc Surg. Autumn 2014;26(3):192-200.

State of the Art: Yolonda Colson. Current Innovations in Sentinel Lymph Node Mapping for the Staging and Treatment of Resectable Lung Cancer. Semin Thorac Cardiovasc Surg. Autumn 2014;26(3):201-209.

State of the Art: Prasad Adusumilli. The IASLC/ATS/ERS Lung Adenocarcinoma Classification: What the surgeon should know. Semin Thorac Cardiovasc Surg. Autumn 2014;26(3):210-222.

Current Readings: Robert Suh. Percutaneous Ablation for Pulmonary Metastatic Disease. Semin Thorac Cardiovasc Surg. Autumn 2014;26(3):239-248.

Current Readings: Anne Tsao.Window-of-Opportunity Trials for Thoracic Malignancies. Semin Thorac Cardiovasc Surg. 2014;26(4):323-330.

State of the Art: Isabelle Schmitt-Opitz. Induction Therapy for Mesothelioma. Semin Thorac Cardiovasc Surg. Expected publication August 2015.

State of the Art: David Schrump. Precision Therapy for Lung Cancer: Tyrosine Kinase Inhibitors and Beyond. Semin Thorac Cardiovasc Surg. Expected publication August 2015. 